\title{
Многозначность как основа синкретизма предлогов
}

\author{
Гречухина 3.P. \\ Астраханский государственный медицинский университет, \\ Россия, 414000, г. Астрахань, ул. Бакинская, 121 \\ E-mail: grechukhinaz@mail.ru
}

\begin{abstract}
Аннотация. На современном этапе развития филологической науки проблемы теории предлогов, такие как многозначность, семантика и синкретизм названных единиц языка привлекают к себе внимание лингвистов, поскольку ни в русском, ни во французском языке до сих пор нет такого описания семантики предлогов, которое охватывало бы все единицы данного класса слов. Трактовка значений большинства многозначных предлогов в словарных статьях представляется несколько упрощенной, наблюдается разница в толковании и количестве значений, приписываемых тому или иному предлогу в разных словарях. Это препятствует адекватному пониманию, употреблению и переводу предлогов и вызывает трудности при изучении иностранного языка. Несмотря на многочисленность публикаций по проблематике синкретизма, практически отсутствует комплексный анализ явления синкретизма предложных единиц в разноструктурных языках: русском и французском. Цель данной статьи заключается в представлении многозначности предлогов русского и французского языков как основы для возникновения синкретизма предложных значений. Автором рассмотрены примеры синкретизма значений предлогов на материале русской и французской художественной литературы XIXXXI веков. При исследовании применены методы наблюдения, описания, компонентного анализа, обобщения и интерпретации результатов. В ходе работы были выявлены и рассмотрены некоторые виды синкретизма предложных значений, возникших на основе многозначности: а) пространственно-временной, б) пространственно-целевой, в) причинно-целевой, а также условия возникновения данного явления. Результаты исследования демонстрируют, что многозначность, являясь внутренним семантическим свойством предлогов, служит основой для возникновения синкретизма. В синкретическое единство могут вступать как компоненты (семы) одного, так и разных уровней в составе структуры предложного значения. Результаты исследования вносят вклад в развитие теории синкретизма, теории предлогов и предложной семантики.
\end{abstract}

Ключевые слова: значение, контекст, многозначность, отношение, предлог, причина, словосочетание, семантика, цель

Для цитирования: Гречухина 3.Р. 2021. Многозначность как основа синкретизма предлогов. Вопросы журналистики, педагогики и языкознания, 40 (4): 497-509. DOI: 10.52575/2712-74512021-40-4-497-509

\section{Polysemy as the Basis of Syncretism of Prepositions}

\author{
Zemfira R. Grechukhina \\ Astrakhan State Medical Unyversity, \\ 121 Bakinskaya St, Astrakhan 414000, Russian Federation \\ E-mail: grechukhinaz@mail.ru
}

\begin{abstract}
At the present stage of the development of philological science, many topical problems of the theory of prepositions, such as polysemy, semantics and syncretism of these linguistic units, remain unresolved to the end. Thus, there is still no description of the semantics of prepositions, either in Russian or in French, which would cover all the units of this class of words. The explanations in dictionary articles of the polysemy of prepositions seem somewhat simplified, and there is a difference in the
\end{abstract}


number of meanings attributed to one preposition or another in different dictionaries. This prevents prepositions from being adequately understood, used and translated from one language to another, and causes difficulties in learning a foreign language. In spite of numerous publications on syncretism there is practically no comprehensive analysis of the phenomenon of syncretism of prepositional units in different languages: Russian and French, and the theory of syncretism of multi-valued prepositions in these languages is underdeveloped. The aim of this article is to present polysemy of prepositions in Russian and French as a ground for the syncretism of prepositional-propositional meanings. We will consider the examples of prepositional syncretism in Russian and French fiction of the 19-21th centuries. In the course of the research we used descriptive method, methods of component and distributive analysis. The result of the research is the discovery and consideration of some types of syncretic meanings of prepositions: a) spatio-temporal meanings, b) spatio-objective meanings, c) cause-objective meanings, as well as the conditions of this phenomenon origin. It is concluded that ambiguity, which is an intrinsic semantic property of prepositions, is the basis for the syncretism emergence. The syncretic unity can be formed by components (semes) of the same or different levels which make up the structure of prepositional meaning. The results of the study contribute to the development of the theory of polysemy and syncreticism, the theory of prepositions and intensification of the study of prepositional semantics.

Key words: meaning, context, polysemy, relationship, preposition, cause, semantics, purpose

For citation: Grechukhina Z.R. 2021. Polysemy as the Basis of Syncretism of Prepositions. Issues in Journalism, Education, Linguistics, 40 (4): 497-509 (in Russian). DOI: 10.52575/2712-7451-2021-40-4-497-509

\section{Введение}

Интерес лингвистов к исследованию семантики предлогов в различных языках мира в последние десятилетия заметно возрос. Это позволило значительно расширить круг проблем, связанных с данной частью речи, назревших в лингвистической науке и требующих глубокого анализа.

Многочисленные исследования способствовали прояснению некоторых дискуссионных вопросов в этой области, в частности вопроса о наличии у предлогов собственного лексического значения, который в настоящее время признается решенным однозначно: предлоги обладают своеобразным лексическим значением со сложной иерархически организованной структурой. Однако ряд вопросов и по сей день остается открытым. Так, ни в русском, ни во французском языке до сих пор нет многостороннего описания семантики предлогов, которое охватывало бы все единицы данного класса слов. Нет единого мнения ученых по поводу того, какие единицы языка следует считать предлогами, каково их общее количество в русском и во французском языке, каковы их системные связи.

Доработки требует и описание значений предлогов в словарях. Как русский, так и французский язык имеют давнюю и богатую лексикографическую традицию, однако трактовка значений большинства многозначных предлогов в словарных статьях представляется упрощенной и не совсем точной. Наблюдается разница в толковании и количестве значений, приписываемых тому или иному предлогу, от одного словаря к другому. Все это препятствует адекватному пониманию, употреблению и переводу предлогов и создает трудности при изучении иностранного языка.

Вызывает необходимость более глубокого рассмотрения и проблема синкретизма предлогов. Несмотря на многочисленность публикаций по данной проблематике, практически отсутствует комплексный анализ явления синкретизма предложных единиц в разноструктурных языках: русском и французском. Цель настоящей статьи заключается в представлении многозначности как основы для возникновения такого явления, как синкретизм значений предлогов русского и французского языков. 
В ходе исследования были применены следующие методы:

- описательный метод с использованием приемов наблюдения, обобщения исследуемого материала;

- метод компонентного анализа, представляющий собой процедуру разложения значения предлога на семантические компоненты;

- метод дистрибутивного анализа, позволяющий выявить характер линейных связей изучаемых языковых единиц в тексте, в первую очередь их сочетаемость.

Объектами исследования являются многозначность и синкретизм рассматриваемых единиц двух языков.

\section{Многозначность предлогов}

Особенности лексического значения предлогов, которое очень тесно связано со значением грамматическим, специфика их семантической структуры, а также высокая степень полисемии большинства из данных единиц языка вызывают трудности в установлении, анализе, описании и представлении предложных значений.

Факт наличия у предлогов нескольких значений отражен в словарях, при этом в них не всегда разграничены значения и контекстные варианты. Так, например, Д. Беннет отмечает, что почти у каждого предлога в разных словарях разное количество значений. Проблему количества значений (senses), которые возможно «приписать данной лексеме», он называет одной из самых сложных задач семантики предлогов [Bennet, 1975].

В настоящем исследовании мы исходим из того, что единицы языка обладают принципиальной способностью быть многозначными. Вероятно, у единиц языка может быть одно значение, объединяющее и отражающее все контекстные варианты употребления данной единицы, но значения выбранных для данного исследования предлогов русского и французского языков в большинстве случаев несводимы к одному значению, то есть они многозначны. Полисемия является внутренним семантическим свойством предлогов в отличие от синонимии, антонимии и омонимии, представляющих собой проявление внешних системных семантических связей и отношений между разными единицами.

У исследователей в области лексикологии прочно утвердилось мнение, что значения многозначных слов образуют «понятийные сферы», компоненты которых связаны общим смысловым стержнем. Многозначное слово представляет собой микросистему, в которой значения взаимосвязаны и взаимообусловлены. Взаимосвязь значений предлогов невероятно сложна и недостаточно изучена. Академик В.В. Виноградов в книге «Русский язык» говорил, что «...в толковых словарях русского языка коллекционируются группы значений отдельных предлогов» [Виноградов, 2001, с. 561].

Многие лингвисты обращались к этой проблеме, решая её с той или иной стороны, применяя разные подходы и методы (парадигматический и синтагматический, функциональный и топологический подходы, метод компонентного анализа, «сетевые модели», «образ-схемы» многозначного слова и т.п.) [Коновалова, 1989; Маляр, Селиверстова, 1998; Кравченко, 2001; Селиверстова, 2004; Федотова, 2004; Бороздина, 2009; Borillo М., Vieu L., 1992; Vandeloise, 1992, 1994; Cadiot, 1997; Franckel, Paillard, 2007 и др.] Однако до сих пор в вопросах полисемии предлогов, особенностях «устройства» их семантической структуры остается много неясного.

Следуя общепринятому в лингвистике мнению о полисемии как едином смысловом стержне слова, мы считаем, что все значения в семантической структуре той или иной единицы взаимосвязаны и взаимообусловлены. В таких случаях, может быть, уместнее говорить об имплицитности или эксплицитности тех или других сем, так как состав компонентов лексического значения (семный состав) подвижен и изменчив, возможно акцентирование и усиление одних и, наоборот, затухание и исчезновение других, актуализация 
потенциальных сем и появление новых - все это и создает основу полисемии слов [Гак, 1972; Кузнецова, 1989; Кузнецов, 1996].

Все вышесказанное в полной мере относится и к предлогам как русского, так и французского языков, большинство из которых являются многозначными. В.В. Виноградов выделяет 21 вид основных отношений, означаемых предлогами в современном русском языке:

1) локальные (пространственные);

2) темпоральные (временные);

3) комитативные (обозначающие сопровождение, совместность, соучастие);

4) аблятивные (каритивные, выражающие лишение, удаление, отнятие, противопоставление);

5) трансгрессивные (обозначающие переход из одного состояния в другое, выход за пределы чего-нибудь);

6) инхоативно-финитивные (терминологические, определяющие степень, предел, исходную точку, начальный момент чего-нибудь);

7) квантитативные (количественно-определительные);

8) дистрибутивные (разделительные);

9) лимитативные, ограничительные;

10) посессивные (притяжательные, выражающие принадлежность);

11) генетические (генетивные, определяющие источник, состав, происхождение чего-нибудь);

12) компаративные (выражающие сравнение, сопоставление, иногда даже тождество);

13) модальные (образа и способа действия);

14) финальные (целевые);

15) каузальные (причинные);

16) инструментальные;

17) делиберативные (служащие для указания на содержание, повод суждения, на предмет мысли, речи, чувства);

18) отношения внутреннего содержания (включенности, сопричастности);

19) отношения заместительства, функционального пребывания в роли кого-нибудь;

20) отношения внутренней зависимости;

21) отношения приблизительной меры [Виноградов 2001, с. 561].

Г.А. Тер-Авакян выделяет у предлогов французского языка лексические (онтологические и логические) и синтаксические значения (всего 23 вида):

- онтологические, отражающие отношения, реально существующие во внеязыковой действительности независимо от какого бы то ни было наблюдателя (пространственное, временное, орудийное, модальное, цены или стоимости, агентное, объектное, адресатное, трансформативное, причины, следствия и цели);

- логические отношения, привносимые во внеязыковую действительность наблюдателем и представляющие собой результат логических операций (значения сравнения, соответствия - несоответствия, включения - исключения, замещения, условное, распределительное и ограничительное);

- синтаксические (выделительные, атрибутивно-предикативное, предикативнообстоятельственное и аппозитивное) [Тер-Авакян, 1983, с. 12].

Представим наглядно наличие/отсутствие этих значений у каждого из рассматриваемых в нашем исследовании русских и французских предлогов «в», «нa», «à», «dans», «sur» (см. таблицу). 
Значения в семантической структуре предлогов

Meanings in the semantic structure of prepositions

\begin{tabular}{|c|c|c|c|c|c|}
\hline \multirow{2}{*}{$\begin{array}{c}\text { Наименование } \\
\text { предложного значения }\end{array}$} & \multicolumn{5}{|c|}{ Предлоги } \\
\hline & «B» & «на» & «à̀ & «dans» & «sur» \\
\hline локальное (пространственное) & + & + & + & + & + \\
\hline темпоральное (временное) & + & + & + & + & + \\
\hline финальное (целевое) & + & + & + & $\begin{array}{c}+ \text { (в составе слож- } \\
\text { ных предлогов }) \\
\end{array}$ & - \\
\hline каузальное (причинное) & + & + & + & + & + \\
\hline инструментальное (орудийное) & + & + & + & + & + \\
\hline $\begin{array}{l}\text { квантитативное (количествен- } \\
\text { но-определительное, цены или } \\
\text { стоимости) }\end{array}$ & + & + & + & - & - \\
\hline компаративные (сравнение) & + & + & $\begin{array}{c}+ \text { (в составе } \\
\text { сложных } \\
\text { предлогов) }\end{array}$ & - & - \\
\hline делиберативные & + & + & + & + & + \\
\hline $\begin{array}{l}\text { дистрибутивные (разделитель- } \\
\text { ные, распределительные) }\end{array}$ & - & + & + & - & - \\
\hline $\begin{array}{l}\text { трансгрессивные } \\
\text { (трансформативное) }\end{array}$ & + & - & - & - & - \\
\hline $\begin{array}{l}\text { внутреннего содержания } \\
\text { (включенности) }\end{array}$ & + & - & - & - & - \\
\hline условное & - & - & $\begin{array}{c}+ \text { (в составе } \\
\text { сложных } \\
\text { предлогов) }\end{array}$ & - & - \\
\hline $\begin{array}{l}\text { лимитативные, } \\
\text { ограничительные }\end{array}$ & - & - & + & + & - \\
\hline
\end{tabular}

Сводная таблица иллюстрирует, что большая часть значений, например, таких как локальное (пространственное), темпоральное (временное), каузальное (причинное), инструментальное (орудийное), финальное (целевое), делиберативное), присутствуют в семантической структуре практически всех вышеназванных предлогов. Это объясняется, очевидно, тем, что данные значения выражают наиболее значимые понятийные категории человеческого бытия, отражающиеся в семантике предлогов, посредством которых они передаются в языке.

Из таблицы видно, что каждый из предлогов имеет и ряд других значений (например, предлоги «в», «на», «à» имеют квантитативное и компаративное значения, а предлоги «à», «dans»- лимитативное и т.д.). Наличие такого количества значений в семантической структуре исследуемых предлогов подтверждает факт многозначности данных языковых единиц.

По словам В.В. Виноградова, «совершенно очевидно, что исчерпать синтаксические отношения, даже выражаемые только простыми предлогами, в сухом протокольном перечне очень трудно» [Виноградов, 2001, с. 564], «ни в одном другом типе слов, кроме разве сочинительных союзов, не совмещается так много разнообразных значений и оттенков, как в первичных предлогах» [Виноградов, 2001, с. 566]. Это объясняется тем, что значение предлога представляет собой сложноорганизованный комплекс, складывающийся из его собственного индивидуального значения (типа синтаксического отношения), грамматического значения присоединяемой падежной формы и синтаксического значения всей кон- 
струкции, которое также зависит от специфики лексической и грамматической семантики опорного слова, с которым связана словоформа с предлогом.

Вслед за лингвистами Г.А. Шигановой [2001] и Л.А. Миловановой [2009] значение предлога рассматривается нами как сложная иерархически организованная структура, состоящая из сем разного уровня:

- категориальной семы - самое общее значение предлога, его релятивное значение (значение отношения);

- субкатегориальной семы - передает обстоятельственные, объектные и определительные отношения;

- групповой семы - уточняет, конкретизирует субкатегориальные семы, например: локатив, темпоратив, каузатив и т.д. Так, в предлогах русского языка «в» и «на» и французского языка «dans» и «sur» присутствуют групповые семы локатив и темпоратив: гулять в парке - локатив, вернуться в 9 часов вечера - темпоратив; быть на улице - локатив, зайти на пять минут - темпоратив; dans Paris - локатив, dans trois jours - темпоратив; sur le Pont Neuf - локатив, partir sur les dix heures - темпоратив.

- подгрупповой (дифференциальная) семы - конкретное проявление значения предлога в данной предложно-падежной форме.

Исходя из этого, вышеперечисленные отношения (значения) предлогов «в», «на», «à», «dans», «sur» можно отнести к групповым семам. Все они потенциально содержатся внутри их структуры.

Некоторые из них в свою очередь подразделяются на более конкретные семы. Например, пространственная групповая сема (локатив) содержит такие дифференциальные семы, как 'место', 'конечный пункт движения', 'направление движения'; временная сема (темпоратив) - 'момент', 'период времени'.

Категориальная сема, содержащая самое общее значение предлога, присутствует в структуре предложного значения постоянно. Такие же семы, как субкатегориальные, групповые и дифференциальные, являются подвижными, их состав может меняться в зависимости от ситуации и речевых условий, одни будут выходить на передний план, другие, наоборот, отступать на задний или совсем исчезать. В каждом конкретном случае в предлоге будет актуализироваться определенный набор сем (субкатегориальных, групповых, дифференциальных), отличающийся от других случаев употребления этого же предлога. Смеем предположить, что это одна из причин, которой и объясняется трудность представления значения предлогов.

Поскольку выбранные для данного исследования единицы имеют достаточно схожий семный состав, представим их многозначность общей для всех предлогов схемой (см. рисунок) (так как невозможно отразить полное количество субкатегориальных, групповых и дифференциальных сем, схема имеет условный характер и служит лишь для демонстрации сложной иерархической структуры предложного значения).

Из схематического представления структуры русских предлогов «в», «на» и французских «à», «dans», «sur» становится очевидным, что многозначность исследуемых языковых единиц складывается из совокупности сем разного уровня - субкатегориальных, групповых и дифференциальных - и проявляется на всех трех уровнях иерархии.

Многозначность данных предлогов служит фундаментом для возникновения при определенных условиях такого явления, как синкретизм их значений. В нашем исследовании мы рассматриваем семантический синкретизм, поэтому для нас представляют интерес значения семантического уровня - это групповые и дифференциальные семы. Анализ примеров показал, что в синкретичное целое часто вступают между собой групповые семы предложного значения, однако можно наблюдать и межуровневый синтез - это синкретизм групповых и дифференциальных сем. 


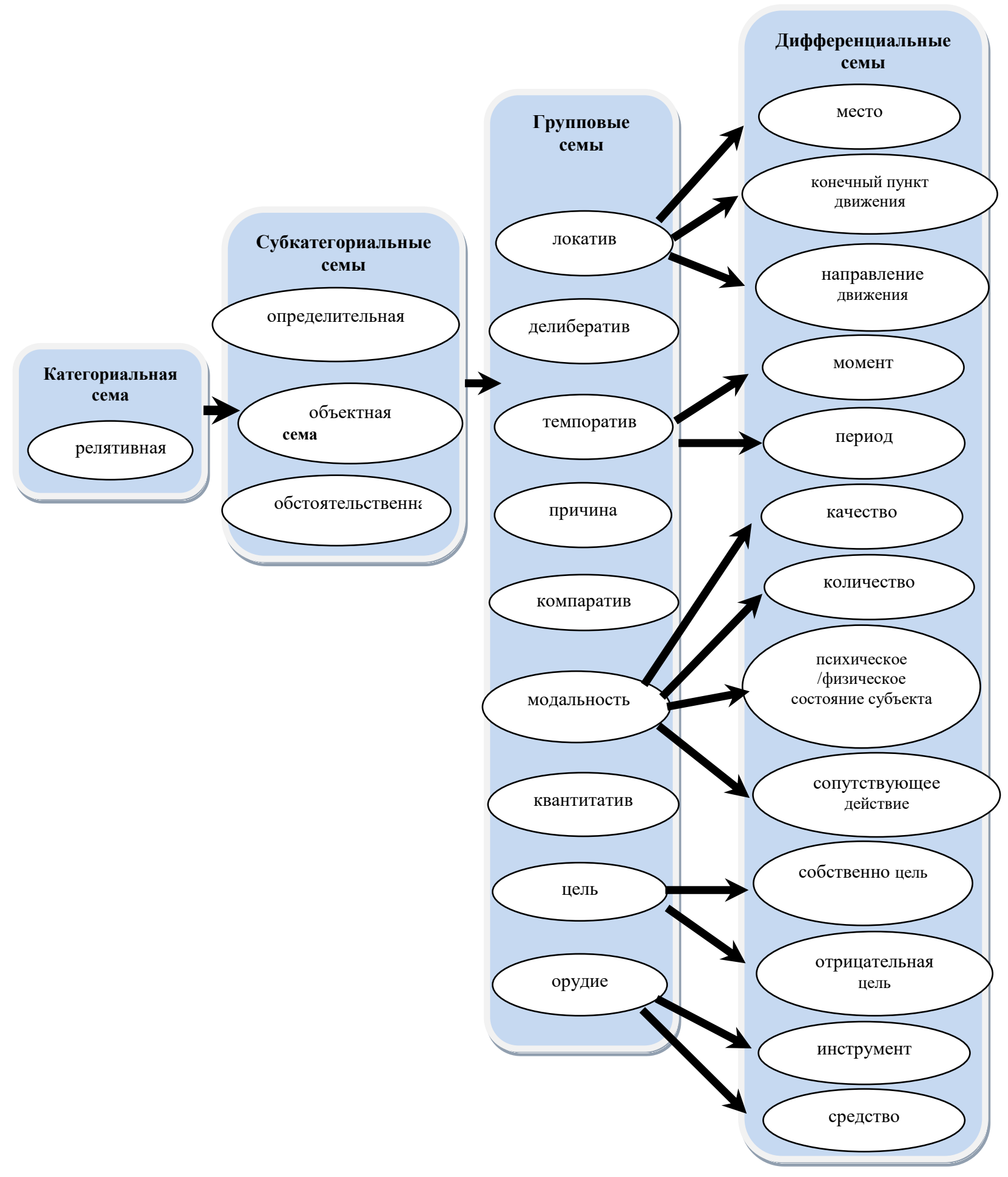

Семный состав многозначного предлога

Component composition of a polysemantic preposition

Таким образом, мы рассматриваем многозначность предлога как совокупность сем разного уровня. В нашей работе мы исследуем именно многозначные предлоги русского и французского языков, поскольку полагаем, что многозначность, являясь их внутренним семантическим свойством, служит основой для возникновения синкретизма.

Обладая многозначностью как совокупностью сем разного уровня, предлог в определенных условиях способен вычленять и актуализировать в своей сложной семантиче- 
ской структуре несколько сем одновременно, совмещение которых и ведет к возникновению синкретизма.

\section{Синкретизм предлогов}

Синкретизм (syncretismos) в переводе с греческого означает соединение. «Словарь лингвистических терминов» дает следующее определение данного явления: «Синкретизм - функциональное объединение разных форм выражения, нейтрализация противопоставлений (оппозиций); совпадение означающих при различных означаемых. Сокращение в процессе развития языка числа категориальных форм, реализующих данную грамматическую категорию, сопровождаемое изменением (расширением) функций сохраняющихся категориальных форм и приводящее к грамматической омонимии. В латинском языке аблатив, выражающий инструментальное и местное значение» [Ахманова, 2021, с. 406].

В.В. Бабайцева трактует синкретизм как «совпадение в процессе развития языка функционально различных грамматических категорий и форм в одной форме; совмещение (синтез) дифференциальных структурных и семантических признаков единиц языка (некоторых разрядов слов, значений, предложений, членов предложения и др.), противопоставленных друг другу в системе языка и связанных явлениями переходности» [Бабайцева, 1990, с. 446].

В ходе исследования были выделены следующие виды синкретизма предложных значений:

1. Синкретизм пространственного и временного значений.

2. Синкретизм пространственного и целевого значений.

3. Синкретизм целевого и причинного значений.

Пространственно-временной синкретизм свойствен как предлогам русского, так и предлогам французского языка и возникает в условиях:

a) когда предлог вводит имя существительное, обозначающее событие с пространственными и временными параметрами;

б) когда предлог связывает два имени существительных событийной семантики.

Схематично покажем типы сочетаний, в которых чаще всего встречается пространственно-временной синкретизм значений рассматриваемых предлогов. Нами было выявлено два типа сочетаний:

a) $\operatorname{Pr}+\operatorname{Nom}$ (где $\operatorname{Pr}$ - предлог, Nom - имя существительное), например:

Они познакомились на свадьбе [Токарева, 2003, с. 13];

б) Nom 1 + Pr + Nom 2, например:

Пусть наградой за все понесенные мною труды в скитаньях по вселенной будут молитвы за меня благочестивых правоверных... [Ян, 1983, с. 88].

Обязательным условием возникновения пространственно-временного синкретизма у русских предлогов «в» и «на» является наличие формы предложного падежа имени существительного. Поскольку во французском языке отсутствует падежная система, данное условие не значимо для возникновения синкретизма значений пространства и времени у французских предлогов «à», «dans» и «sur».

Прозвище Мерген - меткий стрелок он получил в ханской школе [Хабибуллин. 2005, c. 190].

Вика и в Москве здорово смотрелась, видная баба, ничего не скажешь [Рыбаков, 2004, c. 218].

В России сели на теплоход, который делает круиз по Волге [Токарева, 1995, с. 165].

Et bien, c'est moi qui lui ai appris la stratégie à l'Ecole de Guerre. (Это я научил его стратегии в Военной школе) [Дрюон, 1975, с. 93].

Il connaissait Gerhardt par hasard, il l'avait rencontré à Bayreuth, je crois, et il l'aimait bеаисоир. (Он познакомился с Герхардом случайно, он его встретил в Бейруте, я думаю, и он его очень любил) [Sagan, 1986, p. 165]. 
- ...иne balle qui m’a éraflé aи Maroc (...nуля, которая поцарапала меня в Марокко) [Дрюон, 1975, с. 93].

Sur le trottoir, Baudu n'adressa pas la parole à sa nièce. (На тротуаре Бодю не сказал племяннице ни слова) [Золя, 1956, с. 22].

На уровне компонентов значения пространственно-временной синкретизм выражается в соединении в семантической структуре предлогов групповой семы 'время' и дифференциальной (подгрупповой) семы 'местоположение'.

Пространственно-целевой синкретизм обнаруживают предлоги русского языка «в» и «на». Во французском языке он проявляется только у предлога «à», предлоги «dans» и «sur» не проявляют данный вид синкретизма.

Исследование показало, что синкретизм пространственного и целевого значений предлогов русского и французского языков возникает в следующих сочетаниях типа б) $\mathrm{Vb}$ $+\operatorname{Pr}+\mathrm{N}$ : «пойти/поехать на рыбалку, охоту, прогулку, на работу, службу»; «пойти/отправиться на (в) разведку, поиски, задание»; «прийти на помощь, выручку»; «броситься/кинуться в погоню, в преследование»; «aller/partir à la chasse, à la pêche, à la promenade, au travail, au service», à la poursuite, à la recherche».

Пространственно-целевой синкретизм возникает:

a) при наличии имени существительного, содержащего в своем значении сему 'цель', которая чаще всего присутствует в них имплицитно и осознается говорящими лишь в процессе коммуникации, т.е. домысливаются исходя из опыта;

б) при наличии глагола, содержащего в своей семантике подгрупповую сему 'направленное движение вперед', которая входит в более крупную в иерархическом отношении групповую сему 'пространство'.

Отпустите меня на поиски моей единственной, а дальще уж я сам [Хабибуллин, 2005, c. 332].

Поэтому пойдем на служение к Чингисхану [Ян, 1983, с. 141]

Азаты Тубыкбая-багадура бросились в погоню [Хабибуллин, 2005, с. 361].

Mylord, allons au secours de mon père! (Милорд, отправимся на помощь моему отuy!) [Verne, c. 143].

- Non, je vais mettre mes escarpins pour aller à la danse. (Нет, я собираюсь обуть туфли-лодочки, чтобы пойти на танцы) [Stendhal, 1953, с. 76].

На уровне компонентов значения пространственно-целевой синкретизм выражается в соединении в семантической структуре предлогов групповых сем 'пространство' и 'цель'. Обязательным условием возникновения пространственно-целевого синкретизма у русских предлогов «в» и «на» является наличие формы винительного падежа имени существительного.

Причинно-целевой синкретизм у русских предлогов «в» «на» и у французских «à», «dans» и «роиr» возникает:

a) при наличии имени существительного, сочетающего в себе причинную и целевую семантику;

б) при наличии глагола общения или эмоционального глагола.

Обязательным условием возникновения причинно-целевого синкретизма у русских предлогов «в» и «на» является наличие формы винительного падежа имени существительного. Данный вид синкретизма не присущ французскому предлогу «sur».

Отеи решил, видно, чтобы сын поездил на своем саврасом иноходие хоть день-два на прощание [Айтматов, 2007, с. 407] - цель + причина.

Из дверей выглядывали лица сановников, толпившихся в ожндании ханской милости [Ян, 1983, с. 35] - цель + причина.

Nous sommes tous réunis dans le souvenir ému d' Antoine. (Мы все собрались в память Антуана - можно трансформировать: чтобь вспомнить Антуана / ради памяти Антуана) [Балашова, Балашов, 1981, с. 38] 
Nous sommes des hommes, nous aimons bien Antoine, nous sommes là pour lui... (Mbl люди, мы очень любим Антуана, мы здесь для него /из-за него / ради него...) [Балашова, Балашов, 1981, с. 38].

На уровне компонентов значения причинно-целевой синкретизм выражается в соединении в семантической структуре предлогов групповых сем 'причина' и 'цель'.

Синкретизм предлогов не возникает:

а) при нарушении/изменении условий (имя существительное или глагол не содержат соответствующих семантических компонентов; имя существительное употребляется в другом падеже);

б) при наличии сразу двух лексических средств, отдельно выражающих каждое из значений.

Завтра спрошу в школе [Шукшин, 2010, с. 142] - значения времени и пространства выражены отдельно.

Багадур Тубыкбай привел брата в ханскую школу, когда ему стукнуло семь лет [Хабибуллин. 2005, с. 190] - имя существительное употребляется в другом падеже.

В Москве приземлились в полдень 23 августа [Рыбаков, 2004, с. 223] - Значения времени и пространства выражены отдельно.

Получив распоряжение выехать в Москву, Шарок задумался [Рыбаков, 2004, с. 98] - имя существительное употребляется в другом падеже.

За это время немиы потеряли четверть своих вооруженных сил в России [Рыбаков, 2004, с. 48] - значения времени и пространства выражены отдельно.

Революция застала его за границей, и много лет он пытался вернуться в Россию [Рубина, 2021, с. 142] - имя существительное употребляется в другом падеже.

Девочка и мальчик лет одиннадцати-двенадцати уили на поиски в кухню, мальчик кашлял [Рыбаков, 2004, с. 9] - значения времени и пространства выражены отдельно.

Каганович, с ненавистью глядя на Литвинова холодными голубыми глазами, обвинил его в том, что в погоне за дешевой популярностью у западной буржуазии Литвинов поступился интересами Советского Союза [Рыбаков, 2004, с. 163] - только значение цели.

То же самое наблюдаем и во французском языке:

Et voilà que dans l'après-midi déjà c'est à la chambre de Pétillon qu'on s'en prend [Сименон, 1974, с. 193]. (И вот уже днем в комнате Петийона мы нападаем (атакуем, хватаем его)) - значения времени и пространства выражены отдельно.

- Dis donc, Maigret, je crois que c'est ton ami qui fait les cent pas sur le trottoir. (Скажи-ка Мегрэ, я думаю, что это твой друг прогуливается на тротуаре) [Simenon, 2012, p. 83] - только пространство.

Le lendemain, je l'attendis vainement pour une promenade. (На следующий день я напрасно ждал её на прогулку) [Bordeaux, 1990, p. 45] - только значение цели.

\section{Заключение}

Материалы проведенного исследования демонстрируют, что многозначность, являясь внутренним семантическим свойством предлогов, служит основой для возникновения синкретизма. В синкретическое единство могут вступать как компоненты (семы) одного, так и разных уровней в составе структуры предложного значения.

На компонентном уровне были выявлены следующие синкретичные единства:

1) групповая семы 'время' + дифференциальная (подгрупповая) сема 'местоположение';

2) групповая сема 'пространство' + групповая сема 'цель';

3) групповая сема 'причина' + групповая сема 'цель'.

На наш взгляд, здесь можно говорить о разноуровневом семантическом синкретизме, который возникает на основе многозначности исследуемых предлогов, что свидетельствует о подвижности семного состава их лексического значения, его гибкости. 


\section{Список источников}

1. Ахманова О.С. 2021. Словарь лингвистических терминов. M., URSS, 576 с.

2. Айтматов Ч. 2007. Плаха. СПб., Издательский Дом «Азбука-классика», 496 с.

3. Бабайцева В.В. 1990. Синкретизм. В кн. Лингвистический энциклопедический словарь. Под. ред. В.Н. Ярцевой. М., Советская энциклопедия, 682 с.

4. Балашова Т.В., Балашов В.П. 1981. Современная французская новелла XX века = Conteurs francais du XXé siècle, 1945-1977. М., Прогресc, 494 c.

5. Дрюон М. 1975. Рассказы = Nouvelles. Под ред. Л.Ю. Виндт. Л., «Просвещение», Ленинградское отделение, $221 \mathrm{c.}$

6. Золя Э. 1956. Счастье дам = Au Bonheur des Dames. Под ред. О. Ловцовой. М., Изд-во лит. на иностр. яз., $471 \mathrm{c.}$

7. Рубина Д. 2021. На Верхней Масловке. М., Эксмо, 448 с.

8. Рыбаков А. 2004. Прах и пепел. Кн. 3. Дети Арбата: в 3 кн. СПб., Амфора, 480 с.

9. Сименон Ж. 1974. Мегрэ сердится = Maigret se Fache. Л., «Просвещение», 231 с.

10. Токарева В.С. 1995. Вместо меня. М., ЭКСМО, 368 с.

11. Токарева В.С. 2003. Розовые розы. М., ООО «Издательство АСТ», 380 с.

12. Хабибуллин М. 2005. Сказание о Казани и дочери хана. Казань, Татарское книжное издательство, $608 \mathrm{c}$.

13. Шукшин В. 2010. Калина красная. СПб., Амфора, 475 с.

14. Ян В. 1983. Чингисхан. Челябинск, Юж.-Урал. кн.изд-во, 312 с.

15. Bordeaux H. 1990. La robe de laine. Éditions du Rocher, 238 p.

16. Sagan F. 1986. De guerre lasse. Éditions Gallimard, 220 p.

17. Simenon G. 2012. La première enquête de Maigret $=$ Первое дело Мегрэ. Коммент. и слов. О. П. Панайотти. Санкт-Петербург, КАРО, 287 с.

18. Stendhal. 1953. La chartreuse de Parme. Москва, Издательство иностранной литературы, $548 \mathrm{c}$.

19. Verne J. Les enfants du Capitaine Grant. URL: https://bookscafe.net/read/verne_julesles_enfants_du_capitaine_grant-261171.html\#p1 (дата обращения: 30.08.2021)

\section{Список литературы}

1. Бабайцева В.В. 2005. Избранное. 1955-2005. М., Ставрополь, Издательство СГУ, 515 с.

2. Бороздина И.С. 2009. Вариативность исследовательских подходов к изучению предложной семантики: история вопроса. В кн.: Ученые записки. Электронный научный журнал Курского государственного университета, 2 (10): 83-92. URL: http://scientific-notes.ru/\#newnumber?id=10 (дата обращения 25.02.2020).

3. Виноградов В.В. 2001. Русский язык (Грамматическое учение о слове). Под ред. Г.А. Золотовой. М., Русский язык, 720 с.

4. Гак В.Г. 1972. К проблеме семантической синтагматики. В кн.: Проблемы структурной лингвистики. М., Изд-во АН СССР, с. 367-395.

5. Гак В.Г. 2014. Теоретическая грамматика французского языка. М., Добросвет, 832 с.

6. Кравченко Н.П. 2001. Семантико- и текстообразующие функции русских предлогов: На материале языка художественной литературы и СМИ: дисс. ... д-ра филол. наук: 10.02.01, 10.01.10. Краснодар, 2001, 273 с.

7. Коновалова Т.Е. 1989. Функционально-стилистическая обусловленность использования служебных слов (на материале предлогов с широкой семантикой в русском и английском языках). В кн.: Язык и общество. Роль экстралингвистических факторов в развитии лексических подсистем. Саратов, Изд-во Саратовского университета, с. 40-47.

8. Кузнецов А.М. 1986. От компонентного анализа к компонентному синтезу. Москва, Наука, 123 с.

9. Кузнецова Э.В. 1978. О соотношении многозначности и функциональной эквивалентности слов. Науч. докл. высш. школы Филол. науки, 2: 97-103.

10. Кузнецова Э.В. 1989. Лексикология русского языка. М., Высшая школа, 216 с.

11. Лакофф Д. 2004. Метафоры, которыми мы живем. Москва, УРСС, 252 с.

12. Маляр Т.Н., Селиверстова, О.Н. 1998. Пространственно-дистанционные предлоги и наречия в русском и английском языках. München, Verlag Otto Sagner, 345 с. 
13. Милованова Л.А. 2009. Семантико-грамматические свойства и отношения предлога за1, оформляющего винительный падеж, и предлога за2, оформляющего творительный падеж, в современном русском языке. Автореф. дис. ... канд. филол. наук. Челябинск, 23 с.

14. Пайар Д. 2000. К вопросу о значении предлога sur. В кн.: Исследования по семантике предлогов. М., Русские словари, С. 153-188.

15. Селиверстова О.Н. 2004. Труды по семантике. Москва, Языки славянской культуры, 959 c.

16. Тер-Авакян Г.А. 1983. Значение и употребление предлогов во французском языке. М., Высшая школа, $240 \mathrm{c.}$

17. Тер-Авакян Г.А. 1993. О взаимных связях предлога и артикля во французском языке. В кн.: Функционально-семантические характеристики предложения в современном французском языке. Пятигорск, Изд-во Пятигор. гос. пед. ин-та иностр. яз., $171 \mathrm{c.}$

18. Федотова M.А. 2004. Семантика предлога Dans в именных сочетаниях в современном французском языке: Когнитивный аспект: автореф. дис. ... канд. филол. наук: 10.02.05. Иркут. государственный лингвистический университет. Иркутск, 2004, 22 с.

19. Шиганова Г.А. 2001. Система лексических и фразеологических предлогов в современном русском языке. Челябинск, Изд-во Челябинского государственного педагогического университета, $454 \mathrm{c}$.

20. Bennet D.C. 1975. Spatial and Temporal Uses of English Prepositions: An Essay in Stratificational Semantics. London, Longman Publishing Group, 235 p.

21. Borillo M., Vieu L. 1992. Comprehensive semantics of the spatial relation dans. In: Rapport IRIT. Toulouse, P. 145-157.

22. Cadiot P. 1997. Les prépositions abstraites en français. Vol. 1. Paris: A. Colin, 295 p.

23. Franckel J.-J., Paillard D. 2007. Grammaire des prépositions. In: J.-J. Franckel, D. Paillard. Paris, Éditions Ophrys, 223 p.

24. Vandeloise C. 1992. Les analyses de la préposition dans: faits linguistiques et effets méthodologiques. In: Lexique, P. 15-40.

25. Vandeloise C. 1994. Methodology and Analyses of the Preposition. Cognitive Linguistics, 5 (2): $157-184$.

\section{References}

1. Babajceva V.V. 2005. Izbrannoe. 1955-2005. [Selected. 1955-2005]. M., Stavropol', Publ. SGU, $515 \mathrm{p}$.

2. Borozdina I.S. 2009. Variativnost' issledovatel'skih podhodov $\mathrm{k}$ izucheniyu predlozhnoj semantiki: istoriya voprosa [Variation of research approaches to the study of prepositional semantics: the history of the issue]. Uchenye zapiski, 2 (10): 83-92. URL: http://scientific-notes.ru/\#new-number?id=10 (Accessed 25.02.2020).

3. Vinogradov V.V. 2001. Russkij yazyk (Grammaticheskoe uchenie o slove). [Russian language (Grammatical doctrine of the word)]. Ed. G.A. Zolotovoj. M., Publ. Russkij yazyk, 720 p.

4. Gak V.G. 1972. K probleme semanticheskoj sintagmatiki. [To the problem of semantic syntagmatics]. In: Problemy strukturnoj lingvistiki [Problems of Structural Linguistics]. Moscow, Publ. AS USSR, 1972, pp. 367-395.

5. Gak V.G. 2014. Teoreticheskaya grammatika francuzskogo yazyka. [Theoretical grammar of the French language]. M., Publ. Dobrosvet, 832 p.

6. Kravchenko N.P. 2001. Semantiko- i tekstoobrazuyushchie funkcii russkih predlogov: Na materiale yazyka hudozhestvennoj literatury i SMI [Semantico- and text-forming functions of Russian prepositions: On the material of the language of fiction and mass media]: diss. ... d-ra filol.: 10.02.01, 10.01.10. Krasnodar, 273 p.

7. Konovalova T.E. 1989. Funkcional'no-stilisticheskaya obuslovlennost' ispol'zovaniya sluzhebnyh slov (na materiale predlogov s shirokoj semantikoj v russkom i anglijskom yazykah) [Functional and stylistic conditionality of the use of function words (on the material of prepositions with wide semantics in Russian and English languages)]. In: YAzyk i obshchestvo. Rol' ekstralingvisticheskih faktorov v razvitii leksicheskih podsistem. [Language and society. The Role of Extra-linguistic Factors in the Development of Lexical Subsystems]. Saratov, Publ. Saratovskogo universiteta, pp. 40-47.

8. Kuznecov A.M. 1986. Ot komponentnogo analiza k komponentnomu sintezu [Lexicology of the Russian language]. Moscow, Publ. Nauka:123 p. 
9. Kuznecova E.V. 1978. O sootnoshenii mnogoznachnosti i funkcional'noj ekvivalentnosti slov [On the relation of polysemanticity and functional equivalence of words]. Nauch. dokl. vyssh. shkoly Filol. nauki, 2: 97-103.

10. Kuznecova E.V. 1989. Leksikologiya russkogo yazyka. [Lexicology of the Russian language]. Moscow, Publ. Vysshaya shkola, 216 p.

11. Lakoff D. 2004. Metafory, kotorymi my zhivem. [Metaphors we live by]. Moscow, URSS, 252 p.

12. Malyar T.N., Seliverstova, O.N. 1998. Prostranstvenno-distancionnye predlogi i narechiya v russkom i anglijskom yazykah. [Spatial-distance prepositions and adverbs in Russian and English]. München, Verlag Otto Sagner, 345 p.

13. Milovanova L.A. 2009. Semantiko-grammaticheskie svojstva i otnosheniya predloga za1, oformlyayushchego vinitel'nyj padezh, i predloga za2, oformlyayushchego tvoritel'nyj padezh, v sovremennom russkom yazyke. [Semantico-grammatical properties and relations of the preposition za1, which forms the accusative case, and the preposition za2, which forms the instrumental case, in the contemporary Russian language]. Avtoref. dis. ... kand. Philological Sciences. CHelyabinsk, 23 p.

14. Pajar D. 2000. K voprosu o znachenii predloga sur [On the meaning of the preposition sur]. In: Issledovaniya po semantike predlogov. [Studies on the semantics of prepositions]. Moscow, M., Publ. Russkie slovari, pp. 153-188.

15. Seliverstova O.N. 2004. Trudy po semantike [Works on Semantics]. Moscow, Publ. YAzyki slavyanskoj kul'tury, $959 \mathrm{p}$.

16. Ter-Avakyan G.A. 1983. Znachenie i upotreblenie predlogov vo francuzskom yazyke. [The meaning and use of prepositions in French]. Moscow, Publ. Vysshaya shkola, $240 \mathrm{p}$.

17. Ter-Avakyan G.A. 1993. O vzaimnyh svyazyah predloga i artiklya vo francuzskom yazyke. [On the mutual relations of the preposition and the article in French]. In: Funkcional'no-semanticheskie harakteristiki predlozheniya $\mathrm{v}$ sovremennom francuzskom yazyke [Functional-semantic characteristics of the sentence in modern French]. Pyatigorsk, Publishing house of the Pyatigorsk State Pedagogical Institute of Foreign Languages, $171 \mathrm{p}$.

18. Fedotova M.A. 2004. Semantika predloga Dans v imennyh sochetaniyah v sovremennom francuzskom yazyke: Kognitivnyj aspect. [Semantics of the preposition Dans in nominative combinations in modern French: Cognitive aspect]: avtoref. dis. ... kand. filol. nauk: 10.02.05. Irkut. gosudarstvennyj lingvisticheskij universitet. Irkutsk, $22 \mathrm{p}$.

19. SHiganova G.A. 2001. Sistema leksicheskih i frazeologicheskih predlogov v sovremennom russkom yazyke. [The system of lexical and phraseological prepositions in the modern Russian language]. CHelyabinsk, Publ. CHelyabinskogo gosudarstvennogo pedagogicheskogo universiteta, $454 \mathrm{p}$.

20. Bennet D.C. 1975. Spatial and Temporal Uses of English Prepositions: An Essay in Stratificational Semantics. London, Longman Publishing Group, 235 p.

21. Borillo M., Vieu L. 1992. Comprehensive semantics of the spatial relation dans. In: Rapport IRIT. Toulouse, P. 145-157.

22. Cadiot P. 1997. Les prépositions abstraites en français. Vol. 1. Paris: A. Colin, 295 p.

23. Franckel J.-J., Paillard D. 2007. Grammaire des prépositions. In: J.-J. Franckel, D. Paillard. Paris, Éditions Ophrys, 223 p.

24. Vandeloise C. 1992. Les analyses de la préposition dans: faits linguistiques et effets méthodologiques. In: Lexique, P. 15-40.

25. Vandeloise C. 1994. Methodology and Analyses of the Preposition. Cognitive Linguistics, 5 (2): $157-184$.

Конфликт интересов: о потенциальном конфликте интересов не сообщалось.

Conflict of interest: no potential conflict of interest related to this article was reported.

\section{ИНФОРМАЦИЯ ОБ АВТОРЕ}

Гречухина Земфира Ришадовна, старший преподаватель кафедры латинского и иностранных языков Астраханского государственного медицинского университета, г. Астрахань, Россия

\section{INFORMATION ABOUT THE AUTHOR}

Zemfira R. Grechukhina, Senior Lecturer, Department of Latin and Foreign Languages. Astrakhan State Medical University, Astrakhan, Russia 